\title{
Motivation of adult female patients seeking orthodontic treatment: an application of Q-methodology
}

This article was published in the following Dove Press journal:

Patient Preference and Adherence

9 February 2015

Number of times this article has been viewed

Xia Tang'

Jiaxin Cai'

Beibei Lin'

Linjie Yao ${ }^{2}$

Feiou $\operatorname{Lin}^{3}$

'School of Stomatology,

2Department of Pedodontics,

${ }^{3}$ Department of Orthodontics,

School of Stomatology, Wenzhou

Medical University, Lu Cheng District,

People's Republic of China
Correspondence: Feiou Lin

Department of Orthodontics, School and Hospital of Stomatology, Wenzhou Medical University, I I3, Xue Yuan West Road, Lu Cheng District, Wenzhou, People's Republic of China

Tel +86 57788063012

Fax +8657788063666

Email linfeiousci@।63.com
Background: Motivation is the impetus for patients to seek orthodontic treatment, affecting adherence, treatment outcomes, and satisfaction. The aim of this study was to assess the motivation of adult female patients seeking orthodontic treatment, and classify the patients according to their motivations.

Methods: This study used Q-methodology as the main tool. Q-samples were collected and categorized (35 items). Forty-two adult female patients were interviewed before treatment as the P-sample, and their responses were categorized into the Q-methodology grid. Participants were asked to rank-order a set of 35 statements (Q-sample) from "agree most" to "disagree most” (Q-sorting). The finished Q-grids were analyzed using PQ method 2.35.

Results: Four main factors were identified based on how adult female patients ranked statements: factor 1, patients who focus on their self-perception of their appearance; factor 2, patients who are concerned about the esthetics and function of their teeth; factor 3, patients who are easily influenced by others; factor 4, patients who want to improve their confidence and avoid negative thoughts caused by their teeth. The remaining patients who had other views did not match any of the above four groups.

Conclusion: The motivations of adult female patients seeking orthodontic treatment are complex. This study found that most adult female patients fell into one of four typical factor groups. Our findings may improve the adherence of adult female patients by developing a more ideal treatment program.

Keywords: adult female patients, orthodontic treatment, Q-methodology

\section{Background}

Orthodontic treatment is a method of aligning the teeth or correcting other irregularities, which can improve health, oral function, appearance, and social well-being. ${ }^{1,2}$ An increasing number of adult patients are now seeking treatment, and females are more concerned about the esthetics of their teeth than males, ${ }^{3}$ leading to a more active demand for treatment in females. Patients who undergo orthodontic treatment in their developmental stage may avoid related conditions such as asymmetry of the face, sleep-related breathing disorders, and developmental dyslexia, ${ }^{4,5}$ while patients seeking treatment as adults have missed the optimal treatment time. There is a lack of research on the motivation of adults seeking orthodontic treatment, ${ }^{6}$ especially in women. People seeking treatment differ in their thoughts, emotions, and behaviors, and these differences also contribute to individual motivation. Motivation stems from several sources, and can be defined as a concept that describes the conscious or unconscious stimulus for action toward a desired goal. ${ }^{7}$ Both positive and negative motivations are correlated with adherence. ${ }^{8}$ The motivation to seek treatment in this research is 
a positive motivation, hereinafter referred to as motivation. When motivation is lost, there is a danger that a patient's compliance will suffer, and this might lead to premature termination of treatment or a compromised result. ${ }^{8,9}$ Thus, it is important that clinicians should understand the motives and personality traits of their patients; this will facilitate a mutually beneficial alliance. ${ }^{10}$

Q-methodology allows subjects to directly express their inner thoughts. Since the subjects and the opinions are stated as variables and samples, the research takes the subjects' views as the core, presenting their own in-depth subjective consciousness and thoughts. ${ }^{11}$ This strategy allows a subjective view of the data, but is neither a qualitative nor a quantitative approach. It is acknowledged to be an appropriate tool in motivation research. ${ }^{9}$ Therefore, in this study, we aimed to use Q-methodology to assess the motivations of adult female patients who decide to have orthodontic treatment, and to group them according to common opinions. Our objective was to develop a set of specific strategies for use in counseling before treatment. The results may offer effective strategies that could be selected for each patient, and the findings may improve patient adherence and reduce the risk of patient dissatisfaction with the outcomes of treatment.

\section{Materials and methods}

Adult female patients over 18 years of age were selected for this study. Patients with cleft lip or palate, craniofacial syndromes, orthognathic or prosthodontic needs, and amentia were excluded, because they are not representative of the typical orthodontic population. All patients were recruited at the first visit between October 2013 and May 2014 from the Orthodontic Department of Wenzhou Medical University, Wenzhou, People's Republic of China. Ethical approval for the study was granted by the health research ethics board at the School of Stomatology, Wenzhou Medical University (WYKQ2014001), and all participants signed a consent form.

\section{Construction of Q-sample}

Q-sampling involved gathering views from adult female patients about their reasons for seeking orthodontic treatment. Subjective viewpoints were collected by interviewing patients in the orthodontic department. In preparation, we reviewed the relevant orthodontic literature. ${ }^{12}$ Two researchers trained in the process of in-depth interviewing interviewed 80 patients of all ages and backgrounds in the orthodontic department. A list of 50 viewpoints was collected during the interviews, then two professors of orthodontics and three methodologists identified repetition of viewpoints and eliminated duplications. The structure of the sample of Q-statements must represent the entire population of statements or "concourse". ${ }^{12}$ The statements are colloquial rather than technical to ensure that participants can easily understand them. The number of the Q-sample ranges between 30 and 140, according to the research conditions. ${ }^{13}$ To ensure the content validity of the Q-sample, it is usually reviewed by experts and checked by a pilot study. Ultimately, 35 statements (the Q-sample) were created to represent the concourse. These statements were numbered randomly and printed on 35 separate cards.

\section{Selection of P-sample}

Brown ${ }^{12}$ recommended that 40-60 participants are sufficient for a P-sample. The selection of our P-sample was guided by the aim to maximize expression of a variety of viewpoints. Forty-two adult female patients were recruited according to the selection criteria. The patient demographics confirmed their breadth and diversity, as shown in Table 1. The mean age of patients in this study was between 25 and 26 years, consistent with previous studies. ${ }^{14,15}$

\section{Q-sorting}

Participants were given a Q-sample card and sorting instruction sheets with demographic information forms on the back. Firstly, participants were instructed to read all the Q-statements to ensure they completely understood all of them. Next, they were asked to classify the statements into three groups (agree, disagree, and uncertain). The participants

Table I Demographics of participants $(n=37)$

\begin{tabular}{|c|c|c|c|c|}
\hline & Factor I & Factor 2 & Factor 3 & Factor 4 \\
\hline Eigenvalues & 12.337 & 3.878 & 2.944 & 2.671 \\
\hline Variance \% & 22.754 & 10.931 & 4.196 & 3.576 \\
\hline Cumulative \% & 22.754 & 33.684 & 43.675 & 52.191 \\
\hline \multicolumn{5}{|l|}{ Age, years } \\
\hline $18-24$ & 9 & 3 & 4 & 2 \\
\hline $25-30$ & 6 & I & 3 & 2 \\
\hline$>30$ & 5 & I & 0 & 1 \\
\hline \multicolumn{5}{|l|}{ Education background } \\
\hline Illiterate/primary school & I & 0 & 1 & I \\
\hline Secondary school & 5 & I & 1 & 2 \\
\hline Tertiary & 14 & 4 & 5 & 2 \\
\hline \multicolumn{5}{|l|}{ Employment status } \\
\hline Unemployed & 9 & I & 6 & 2 \\
\hline Employed & 11 & 4 & I & 3 \\
\hline \multicolumn{5}{|l|}{ Marital status } \\
\hline Single & 8 & 3 & 6 & 2 \\
\hline Married & 12 & 2 & I & 3 \\
\hline $\mathrm{n}$ & 20 & 5 & 7 & 5 \\
\hline
\end{tabular}


were then asked to rank the statements on an 11-point scale (Figure 1), placing the statements most relevant to them in the far left column $(+5)$ and the statements least relevant to them in the far right column $(-5)$. Subsequently, they were asked to complete the next column by choosing the remaining statements that were most and least relevant to them. This procedure was repeated until the remaining statements were placed in the neutral zone $(0)$ of the column. Participants were instructed to take as much time as they needed until they were satisfied with the sorting results. To ensure the reliability of the study, the interview was conducted on a one-on-one basis.

\section{Statistical analysis}

We used PQ Method 2.35 to analyze the Q-sorts. Notable factors were extracted by centroid factor extraction and varimax rotation. Factors were extracted using the following criteria: there were at least four or five defining sorts and the eigenvalues had to be greater than $1 .{ }^{12}$ A composite Q-sort was created for each factor, which reflects the typical profile of participants who loaded on a particular factor. There were distinguishing statements with which a particular factor agreed or disagreed statistically more strongly than other factors. Distinguishing statements that were significant at $P<0.05$ are indicated with a single asterisk, and those at $P<0.01$ are indicated with a double asterisk.

\section{Results}

Analysis of the participants' Q-sorts resulted in twelve factors with eigenvalues above 1.0. The cumulative variance of twelve factors accounted for $82.74 \%$. Finally, we extracted a four-factor solution (Figures 2-5), by which participants were classified into four categories. The titles given to each factor broadly describe the views expressed in that factor.

The cumulative variance of factors we extracted accounted for $52.191 \%$ in the correlation matrix. Thirtyseven participants were defined according to the four factors, and the remaining five were confounded, ie, they loaded significantly on more than one factor. Details of the sociodemographic characteristics of the final P-samples are summarized in Table 1. The statements are shown in Table 2, including the distinguishing statements.

\section{Factor I: Patients who focus on self- perception of their appearance}

Figure 2 illustrates the ideal grid for factor 1, which accounted for $22.754 \%$ of total variance. Twenty participants loaded on this factor. Among these participants, five were over 30 years of age. More details are shown in Table 1.

These patients strongly agreed with the statements about wanting to improve their self-image when they smile (S20:+4**) and wanting to be more attractive $(\mathrm{S} 15:+5)$. They wanted to make themselves feel better (S17: +4). This group of patients agreed least with the following statements: "I am embarrassed because I spit on people when I talk to them" (S5: $-4 * *)$, "I always bite my tongue when I talk" (S27: $\left.-5^{* *}\right)$, and "My teeth make eating difficult" (S8: $-4 * *)$.

\section{Factor 2: Patients who are concerned about the esthetics and function of their teeth}

Figure 3 illustrates the ideal grid for factor 2, on which five participants loaded, accounting for $10.931 \%$ of total variance with the Q-sorts. This group of patients were significantly concerned about the protrusion of their dentition $(\mathrm{S} 25:+5)$ and wanted a row of perfect teeth $(\mathrm{S} 16:+4)$. Compared with other groups, this group of patients showed the greatest agreement with the following statements: "It's hard to chew food well" (S26: $+2 *)$ and "My relatives are also having orthodontic treatment" (S21: $+2 * *)$. They agreed least with the following statements: "It's so hard to keep teeth clean and they may get decay" (S28: $-4 *)$ and "Wearing braces could help me lose weight by eating less" (S11: $\left.-3^{*}\right)$.

\section{Factor 3: Patients who are easily influenced by others}

Figure 4 illustrates the ideal Q-grid for factor 3, on which seven participants loaded. The total variance with the Q-sorts

\begin{tabular}{|c|c|c|c|c|c|c|c|c|c|c|}
\hline \multicolumn{9}{|c|}{ Agree most } & \multicolumn{2}{|c|}{ Disagree most } \\
\hline+5 & +4 & +3 & +2 & +1 & 0 & -1 & -2 & -3 & -4 & -5 \\
\hline & & & & & & & & & & \\
\hline & & & & & & & & & & \\
\hline & & & & & & & & & & \\
\hline & & & & & & & & & & \\
\hline
\end{tabular}

Figure I Eleven-point scale. 


\begin{tabular}{|c|c|c|c|c|c|c|c|c|c|c|}
\hline \multicolumn{9}{|c|}{ Agree most } & \multicolumn{2}{|c|}{ Disagree most } \\
\hline+5 & +4 & +3 & +2 & +1 & 0 & -1 & -2 & -3 & -4 & -5 \\
\hline \multirow[t]{5}{*}{$\mathrm{S} 15$} & $\mathrm{~S} 20^{* *}$ & S16 & S35 & S19** & S7 & $\mathrm{S} 29$ & $\mathrm{~S} 21$ & S9** & S8** & $\mathrm{S} 27^{* *}$ \\
\hline & $\mathrm{S} 17$ & S12* & $\mathrm{S} 23$ & S26* & S1 & $\mathrm{S} 2$ & S28* & $S 4^{* *}$ & S5** & \\
\hline & & S14 & $\mathrm{S} 18$ & $\mathrm{~S} 13$ & S6 & S33 & $\mathrm{S} 10$ & S3 & & \\
\hline & & & $\mathrm{S} 25^{* *}$ & S32 & S31 & S11* & S34 $4^{* *}$ & & & \\
\hline & & & & $\mathrm{S} 22$ & $\mathrm{~S} 30^{* *}$ & S24* & & & & \\
\hline
\end{tabular}

Figure 2 Q-grid for factor I. Patients who focus on self-perception of their appearance.

Notes: *Distinguishing statement significant at $P<0.05$; **distinguishing statement significant at $P<0.01$. Bold type indicates distinguishing statements for factor $I$ compared with other factors (factor 2, 3 and 4).

Abbreviation: S, statement.

accounted for $4.196 \%$. Compared with the other groups, this group of patients showed greatest agreement with the following statements: "Other non-orthodontic doctors recommended that I have orthodontic treatment" (S34: $+3 * *)$; "My friends suggested that I have orthodontic treatment" (S33: $\left.+2^{* *}\right)$; "My family suggested that I have orthodontic treatment" (S30: $+4 *)$; "I attended for treatment because my friends are also being treated" (S31: $+2 * *)$; and "There is a gap between my teeth" ( $\left.\mathrm{S} 3:+3^{* *}\right)$. These participants disagreed most with the statements: "Irregular teeth affect my daily life" (S1: $-2 *)$; "My clients do not like me because of my appearance" (S2: $\left.-3^{*}\right)$; and "My teeth are protruding" (S25: $-3 * *)$.

\section{Factor 4: Patients who want to improve their confidence and abandon negative thoughts caused by their teeth}

Figure 5 illustrates the ideal Q-grid for factor 4. This factor accounted for $3.576 \%$ of total variance with the Q-sorts, and five patients showed significant loading with this factor. The main perspectives highlighted by factor 4 involved negative thoughts caused by their teeth, such as "I am not willing to talk to other people because of my teeth" $\left(\mathrm{S} 10:+3^{* *}\right)$, "I do not like smiling because of my teeth" $\left(\mathrm{S} 13:+3^{* *}\right)$, and "I have to cover my mouth when I laugh" (S32: $\left.+4^{* *}\right)$. This group of patients agreed most with the following statements: "I want a row of perfect teeth" $(\mathrm{S} 16:+4)$ and "My teeth are protruding" (S25: +5$)$.

\section{Discussion}

Compared with traditional tools, Q-methodology has many features as a qualitative data collection tool. Q-methodology typically employs a small number of respondents instead of a large sample to carry out an investigation, and uses a person-oriented approach to express the subject's inner world in a straightforward manner. The method focuses on issues salient to the subject, and provides opportunities to explore issues in depth. However, Q-methodology also has limitations, in that the completion and analysis of Q-sorting are time-consuming.

The motivations of adult female patients seeking orthodontic treatment are complex. Most of the motivational factors relate broadly to esthetic, functional, and societal concerns, which have already been discussed in previous research. ${ }^{3,9,14}$ Factor 1 subjects were largely concerned about their self-perception of their appearance, as revealed in previous research. ${ }^{16,17}$ In this study, the description of "appearance" is more specific, in that it relates to adult female patients being uncomfortable when they look at themselves in the mirror because of their teeth (S12: $+3 * *)$. Shaw et al found that young adults consider that a normal appearance is viewed more positively with regard to their attractiveness. ${ }^{18}$ They want to make changes to their smile (S20: $+4^{* *}$ ) through orthodontic treatment. We found that these patients had an overriding desire to become more attractive $(\mathrm{S} 15 ;+5)$. The function of teeth is seen as unimportant $\left(\mathrm{S} 27:-5^{* *}\right)$ in this group. Overall, these patients care most about their personal

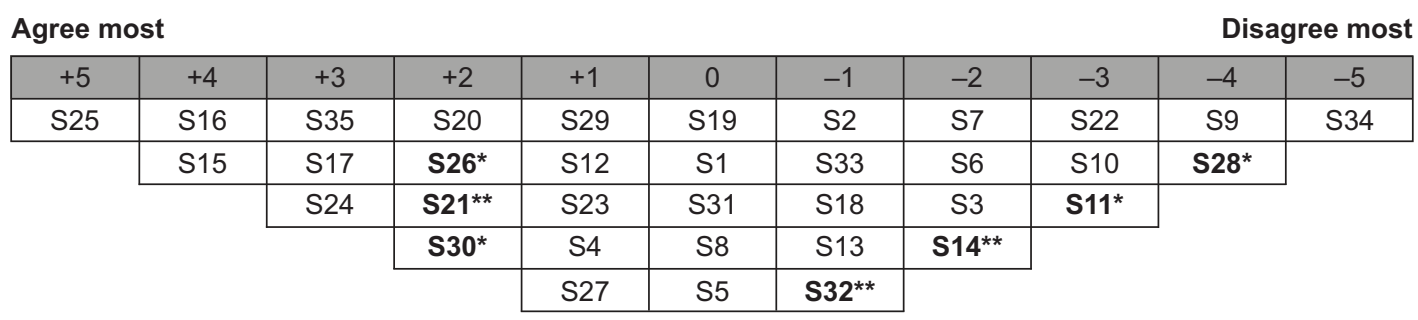

Figure $3 \mathrm{Q}$-grid for factor 2. Patients who are concerned about the esthetics and function of their teeth.

Notes: *Distinguishing statement significant at $P<0.05$; ** distinguishing statement significant at $P<0.01$. Bold type indicates distinguishing statements for factor 2 compared with other factors.

Abbreviation: S, statement. 


\begin{tabular}{|c|c|c|c|c|c|c|c|c|c|c|}
\hline \multicolumn{9}{|c|}{ Agree most } & \multicolumn{2}{|c|}{ Disagree most } \\
\hline+5 & +4 & +3 & +2 & +1 & 0 & -1 & -2 & -3 & -4 & -5 \\
\hline \multirow[t]{5}{*}{$\mathrm{S} 16$} & $\mathrm{~S} 24$ & $\mathrm{~S} 15$ & $\mathrm{~S} 12$ & $\mathrm{~S} 29$ & S20* & S19 & S7 & S2* & S6 & $\mathrm{S} 11$ \\
\hline & $\mathrm{S} 30^{*}$ & S3** & S33** & S35 & $\mathrm{S} 13$ & S26 & S1* & $\mathrm{S} 21$ & S9 & \\
\hline & & S34** & S31** & $\mathrm{S} 23$ & S8 & S28* & S18 & $\mathrm{S} 25^{* *}$ & & \\
\hline & & & $\mathrm{S} 17$ & S32 & S5 & $\mathrm{S} 10$ & S22 & & & \\
\hline & & & & $\mathrm{S} 14^{* *}$ & S4 & $\mathrm{S} 27$ & & & & \\
\hline
\end{tabular}

Figure 4 Q-grid for factor 3. Patients who are easily influenced by others.

Notes: *Distinguishing statement significant at $P<0.05$; **distinguishing statement significant at $P<0.01$. Bold type indicates distinguishing statements for factor 3 compared with other factors.

Abbreviation: S, statement.

view of themselves. When discussing treatment with patients in this group, orthodontists should emphasize the potential positive changes in their appearance to encourage them to cooperate with doctors to achieve a better outcome.

Adult female patients loading on factor 2 were concerned about the esthetics and function of their teeth. Some earlier cross-sectional studies ${ }^{6,14,15}$ reported that these two motivations were crucial in patients attending for treatment. Therefore, it is not surprising that esthetics and function featured prominently in our sample, and that educational background did not influence the subjects' perceptions about esthetics. ${ }^{19}$ The main esthetic problem subjects reported was protruding teeth $(\mathrm{S} 25:+5)$, which may lead to malocclusion and dysfunction. A systematic review of the literature showed that malocclusion influences masticatory efficiency. ${ }^{20}$ Thus it follows that subjects have difficulty in chewing (S26: $\left.+2^{*}\right)$ related to their protruding teeth. They reported wanting a row of perfect teeth $(\mathrm{S} 16:+4)$ to ameliorate these issues. With such patients, orthodontists should realize that esthetics and positive psychosocial impact are accepted as important benefits of orthodontic treatment, ${ }^{21}$ and they should explain clearly that protrusion of the teeth plays a major role in esthetic and functional problems.

The perspectives around factor 3 show that a significant factor for subjects is advice from others. Compared with other groups, these subjects were influenced by recommendations from people other than an orthodontist to seek orthodontic treatment $\left(\mathrm{S} 34:+3^{* *}\right)$; this finding is consistent with previous research in other countries. ${ }^{22}$ Patients in this group, who are almost all single, are strongly influenced by the behaviors and thoughts of their friends (S31: $+2 * * ; \mathrm{S} 33:+2 * *)$. Notably, adult female patients in this group are also concerned about esthetics. They pay less attention to the effects on their social lives (S1: $-2 * ; \mathrm{S} 2:-3 * ; \mathrm{S} 6:-4)$ than the appearance of their teeth $\left(\mathrm{S} 3:+3^{* *}\right)$. This finding is supported by previous research. ${ }^{14,16,17}$ Gaps between the teeth $(\mathrm{S} 3:+3 * *)$ are their main esthetic concern, rather than protrusion (S25: $-3 * *)$, in contrast with factor 2 subjects. With this group of patients, dentists should take time to strengthen communication with both the patient and the accompanying person to successfully play the role of adviser. Clinicians need to impart more information about orthodontic treatment to patients and encourage patients to talk with other adults who have also had treatment. Pabari et $\mathrm{al}^{6}$ found it helpful to provide patients with more information on orthodontic treatment, hence reducing the possibility of divergent thinking between patients and doctors.

Adult females loading on factor 4 emphasized negative thoughts about their teeth (S10: $+3 * * ; \mathrm{S} 13:+3 * * ; \mathrm{S} 32:+4 * *)$. This has not previously been reported as a factor influencing adult patients undergoing orthodontic treatment. ${ }^{6,23}$ Pabari et al ${ }^{6}$ found that a desire to improve their smile was a prime motivating factor, although the deep-seated reasons why patients want to improve their smile was not mentioned. In our study, adult female patients reported low self-esteem and negative thoughts about their appearance, clearly answering the question mentioned above. This sense of low self-esteem may

\begin{tabular}{|c|c|c|c|c|c|c|c|c|c|c|}
\hline \multicolumn{9}{|c|}{ Agree most } & \multicolumn{2}{|c|}{ Disagree most } \\
\hline+5 & +4 & +3 & +2 & +1 & 0 & -1 & -2 & -3 & -4 & -5 \\
\hline \multirow[t]{5}{*}{$\mathrm{S} 25$} & S16 & $\mathrm{S} 13^{* *}$ & $\mathrm{~S} 20$ & S1 & S29 & S7 & S23** & S33 & S9 & S11 \\
\hline & S32** & $\mathrm{S} 10^{* *}$ & S18 & $\mathrm{S} 12$ & S2 & S19 & $\mathrm{S} 26$ & S31* & S34 & \\
\hline & & S14 & S28** & $\mathrm{S} 15^{\star *}$ & S35 & S6 & S21 & S30** & & \\
\hline & & & S22 & S4 & S3 & S8 & S5 & & & \\
\hline & & & & S27 & S24* & $\mathrm{S} 17^{* *}$ & & & & \\
\hline
\end{tabular}

Figure 5 Q-grid for factor 4. Patients who want to improve their confidence and abandon negative thoughts caused by their teeth.

Notes: *Distinguishing statement significant at $P<0.05$; **distinguishing statement significant at $P<0.0$ I. Bold type indicates distinguishing statements for factor 4 compared with other factors.

Abbreviation: S, statement. 
Table 2 Statements and factor scores

\begin{tabular}{|c|c|c|c|c|c|}
\hline \multirow{2}{*}{$\begin{array}{l}\text { Item } \\
\text { number }\end{array}$} & \multirow[t]{2}{*}{ Statements } & \multicolumn{4}{|c|}{ Factor } \\
\hline & & $\mathbf{I}$ & 2 & 3 & 4 \\
\hline SI & Irregular teeth affect my daily life & 0 & 0 & $-2 *$ & I \\
\hline S2 & My clients do not like me because of my appearance & -1 & -1 & $-3 *$ & 0 \\
\hline S3 & There is a gap between my teeth & -3 & -2 & $3^{* *}$ & 0 \\
\hline S4 & I speak with a lisp because of my teeth & $-3 * *$ & 1 & 0 & I \\
\hline S5 & I am embarrassed because I spit on people when I talk to them & $-4 * *$ & 0 & 0 & -2 \\
\hline S6 & It's difficult to have a boyfriend/girlfriend because of my teeth & 0 & -2 & -4 & -1 \\
\hline S7 & It hard for me to find a job because of my ugly teeth & 0 & -2 & -2 & -1 \\
\hline S8 & My teeth make eating difficult & $-4 * *$ & 0 & 0 & -1 \\
\hline S9 & I think orthodontic treatment is very fashionable & $-3 * *$ & -4 & -4 & -4 \\
\hline SIO & I am not willing to talk to other people because of my teeth & -2 & -3 & -1 & $3 * *$ \\
\hline SII & Wearing braces could help me lose weight by eating less & $-I^{*}$ & $-3 *$ & -5 & -5 \\
\hline $\mathrm{SI} 2$ & $\begin{array}{l}\text { I feel uncomfortable when I look at myself in the mirror } \\
\text { because of my teeth }\end{array}$ & $3^{*}$ & 1 & 2 & I \\
\hline $\mathrm{SI3}$ & I do not like smiling because of my teeth & I & -1 & 0 & $3 * *$ \\
\hline $\mathrm{SI} 4$ & I just do not like my teeth & 3 & $-2 * *$ & $I^{* *}$ & 3 \\
\hline SI5 & Orthodontic treatment would make me look more attractive & 5 & 4 & 3 & $I^{* *}$ \\
\hline $\mathrm{SI} 6$ & I want a row of perfect teeth & 3 & 4 & 5 & 4 \\
\hline SI7 & I want to make myself feel better & 4 & 3 & 2 & $-1 * *$ \\
\hline SI8 & I think I would be happier after orthodontic treatment & 2 & -1 & -2 & 2 \\
\hline SI9 & I do not really like myself because of my teeth & $I^{* *}$ & 0 & -1 & -1 \\
\hline S20 & $\begin{array}{l}\text { I hope that I will be able to give a big smile when I have } \\
\text { my photo taken in the future }\end{array}$ & $4 * *$ & 2 & $0^{*}$ & 2 \\
\hline S2I & My relatives are also having orthodontic treatment & -2 & $2 * *$ & -3 & -2 \\
\hline S22 & I feel a little inferior because of my teeth & 1 & -3 & -2 & 2 \\
\hline S23 & I hope to be more popular after orthodontic treatment & 2 & 1 & 1 & $-2 * *$ \\
\hline S24 & I am afraid that my teeth will get worse & $-I^{*}$ & 3 & 4 & $0 *$ \\
\hline S25 & My teeth are protruding & $2 * *$ & 5 & $-3 * *$ & 5 \\
\hline S26 & It's hard to chew food well & $I^{*}$ & $2 *$ & -1 & -2 \\
\hline S27 & I always bite my tongue when I talk & $-5 * *$ & I & -1 & 1 \\
\hline S28 & It's so hard to keep teeth clean and they may decay & $-2 *$ & $-4 *$ & $-I^{*}$ & $2 * *$ \\
\hline S29 & Food often sticks to my teeth, and it feels very uncomfortable & -1 & 1 & 1 & 0 \\
\hline S30 & My family suggested that I have orthodontic treatment & $0 * *$ & $2^{*}$ & $4^{*}$ & $-3 * *$ \\
\hline S3I & I sought treatment because my friends are also being treated & 0 & 0 & $2^{* *}$ & $-3^{*}$ \\
\hline S32 & I have to cover my mouth when I laugh & I & $-I^{* *}$ & 1 & $4 * *$ \\
\hline S33 & My friends suggested that I have orthodontic treatment & -1 & -1 & $2^{* *}$ & -3 \\
\hline S34 & $\begin{array}{l}\text { Other non-orthodontic doctors recommended that I have } \\
\text { orthodontic treatment }\end{array}$ & $-2 * *$ & -5 & $3^{* *}$ & -4 \\
\hline S35 & I realize that irregular teeth negatively affect my appearance & 2 & 3 & 1 & 0 \\
\hline
\end{tabular}

Notes: Factor is the Q-Sort values for each statement.

Abbreviations: Factor I, patients who focus on self-perception of their appearance; Factor 2, patients who are concerned about the esthetics and function of their teeth; Factor 3, patients who are easily influenced by others; Factor 4, patients who want to improve their confidence and abandon negative thoughts caused by their teeth.*Distinguishing statement significant at $P<0.05$; **distinguishing statement significant at $P<0.0$ l.

result from the pressure to look good in today's society and the patient's history of being teased about their appearance. Previous research emphasized the importance of physical appearance to self-esteem. ${ }^{24,25}$ Badran $^{26}$ and Perillo et al ${ }^{27}$ reported that patients who needed orthodontic treatment demonstrated lower self-esteem. Because of low self-esteem or feelings of inferiority, patients in this group had the lowest desire to improve their self-image compared with the other three groups (S15: $+1^{* *}$; S17: $-1^{* *}$; S23: $-2^{* *}$ ). By contrast, they exhibited more self-conscious behavior rather than following the example of others or taking advice (S30: $-3^{* *}$; S31: $\left.-3^{* *}\right)$. Moreover, high self-esteem and selfconfidence tend to be positively correlated with compliance. ${ }^{28}$ Thus, adult patients loading on factor 4 have more difficulty in adhering to treatment. With these patients, orthodontists should emphasize the growing confidence that orthodontic treatment brings, and be sensitive to the patient's needs. Clinicians should be extremely careful about the words they use to communicate with these patients, so as not to embarrass them or hurt their feelings. 
Our data illustrate the motivations of adult females with the aim of reducing the mismatch between clinicians and patients, enhancing communication, and improving patient adherence and satisfaction. Age did not seem to be correlated with seeking treatment, which is consistent with the findings of Southard et al. ${ }^{29}$ This study showed that both internal and external factors played a role in the patient's decision to undergo orthodontic treatment. However, internally motivated patients are more likely to be compliant and satisfied ${ }^{30}$ with treatment outcomes. It has been reported that recognition of certain psychological traits before treatment can be a useful predictor of treatment compliance and enable better treatment outcomes. ${ }^{31}$ Techniques for improving compliance include educating patients about the significance of compliance, treating the patient with respect and establishing a good rapport, ${ }^{32}$ offering immediate rewards, entering into a signed contract with the patient, notating the patient's treatment progress and showing the notes to the patient. ${ }^{33}$ Adult female patients could be asked to complete the Q-sorting process when they present for orthodontic treatment. Dentists would then know what the patient wants and why they are seeking treatment. This would result in more appropriate communication and better rapport with patients, and would improve patient adherence. ${ }^{34}$ This topic should be addressed across a more varied demographic sample before Q-methodology is instituted. Our patients were all adult females in Wenzhou, Zhejiang Province, so further Q-methodology investigation in a more diverse population would be beneficial.

\section{Conclusion}

The concerns of adult female patients seeking orthodontic treatment are complex, and four main factors have been isolated. This research lays the groundwork for future research on the specific type of patient motivation that may help clinicians to improve patient adherence. Q-methodology is an efficient and innovative method which may work well to combine oral medicine and psychological analysis.

\section{Acknowledgments}

This work was supported by grants from Wenzhou Municipal Science and Technology Bureau (Y20130347) and School Project Support from Wenzhou Medical University (wyx201301061). The authors thank Yeon-Sheng Yang and Jun-Chieh Wu (Department of Industrial Design, Huafan University) who provided data interpretation services.

\section{Disclosure}

The authors report no conflicts of interest in this work.

\section{References}

1. Liu Z, McGrath C, Hägg U. The impact of malocclusion/orthodontic treatment need on the quality of life. A systematic review. Angle Orthod. 2009;79(3):585-591.

2. Zhang M, McGrath C, Hägg U. The impact of malocclusion and its treatment on quality of life: a literature review. Int J Paediatr Dent. 2006; 16(6):381-387.

3. Stenvik A, Espeland L, Berset GP, Eriksen HM, Zachrisson BU. Need and desire for orthodontic (re)-treatment in 35-year-old Norwegians. J Orofac Orthop. 1996;57(6):334-342.

4. Perillo L, Esposito M, Caprioglio A, Lucchese A, Santini AC, Carotenuto M. Occlusal traits in developmental dyslexia: a preliminary study. Neuropsychiatr Dis Treat. 2013;9:1231-1237.

5. Carotenuto M, Esposito M, Pascotto A. Facial patterns and primary nocturnal enuresis in children. Sleep Breath. 2011;15(2): 221-227.

6. Pabari S, Moles DR, Cunningham SJ. Assessment of motivation and psychological characteristics of adult orthodontic patients. Am JOrthod Dentofacial Orthop. 2011;140(6):e263-e272.

7. Soanes C, Stevenson A. Concise Oxford English Dictionary. Oxford, UK: Oxford University Press; 2008.

8. Egolf RJ, Begole EA, Upshaw HS. Factors associated with orthodontic patient compliance with intraoral elastic and headgear wear. $A m J$ Orthod Dentofacial Orthop. 1990;97(4):336-348.

9. Prabakaran R, Seymour S, Moles DR, Cunningham SJ. Motivation for orthodontic treatment investigated with Q-methodology: patients' and parents' perspectives. Am J Orthod Dentofacial Orthop. 2012;142(2):213-220.

10. Schabel BJ, McNamara JA Jr, Franchi L, Baccetti T. Q-sort assessment vs visual analog scale in the evaluation of smile esthetics. Am J Orthod Dentofacial Orthop. 2009;135(4 Suppl):S61-S71.

11. Brown SR. Q Methodology and qualitative research. Qual Health Res. 1996;6(4):561-567.

12. Brown SR. Political Subjectivity: Applications Of Q Methodology In Political Science. New Haven, CT, USA: Yale University Press; 1980.

13. Thomas DM, Watson RT. Q Sorting and MIS research: a primer. Communications of the Association of Information Systems. 2002;9(8): 141-156.

14. McKiernan EX, McKiernan F, Jones ML. Psychological profiles and motives of adults seeking orthodontic treatment. Int J Adult Orthodon Orthognath Surg. 1992;7(3):187-198.

15. Sergl HG, Zentner A. Study of psychosocial aspects of adult orthodontic treatment. Int J Adult Orthodon Orthognath Surg. 1997;12(1): $17-22$.

16. Linn EL. Social meaning of dental appearance. J Health Hum Behav. 1966;7(4):298-295.

17. Williams AC, Shah H, Sandy JR, Travess HC. Patients' motivations for treatment and their experiences of orthodontic preparation for orthognathic surgery. J Orthod. 2005;32(3):191-202.

18. Shaw WC, Rees G, Dawe M, Charles CR. The influence of dentofacial appearance on the social attractiveness of young adults. Am J Orthod 1985;87(1):21-26.

19. Zawawi KH, Malki GA, Al-Zahrani MS, Alkhiary YM. Effect of lip position and gingival display on smile and esthetics as perceived by college students with different educational backgrounds. Clin Cosmet Investig Dent. 2013;5:77-80.

20. Magalhaes IB, Pereira LJ, Marques LS, Gameiro GH. The influence of malocclusion on masticatory performance. A systematic review. Angle Orthod. 2010;80(5):981-987.

21. Cunningham SJ, Hunt NP. Quality of life and its importance in orthodontics. J Orthod. 2001;28(2):152-158. 
22. Tulloch JF, Shaw WC, Underhill C, Smith A, Jones G, Jones M. A comparison of attitudes toward orthodontic treatment in British and American communities. Am J Orthod. 1984;85(3):253-259.

23. Shaw WC, Meek SC, Jones DS. Nicknames, teasing, harassment and the salience of dental features among school children. Br J Orthod. 1980;7(2):75-80.

24. Sousa DN, Tsingene F. SAEF - Smile's Aesthetic Evaluation form: a Useful tool to improve communications between clinicians and patients during multidisciplinary treatment. Eur $J$ Esthet Dent 2011;6(2):160-176.

25. Koronczai B, Kokonyei G, Urban R, et al. The mediating effect of self-esteem, depression and anxiety between satisfaction with body appearance and problematic Internet use. Am J Drug Alcohol Abuse. 2013;39(4):259-265.

26. Badran SA. The effect of malocclusion and self-perceived aesthetics on the self-esteem of a sample of Jordanian adolescents. Eur J Orthod. 2010;32(6):638-644.

27. Perillo L, Esposito M, Caprioglio M, Attanasio S, Santini AC, Carotenuto M. Orthodontic treatment need for adolescents in the Campania region: the malocclusion impact on self-concept. Patient Prefer Adherence. 2014;19(8):353-359.
28. Mehra T, Nanda RS, Sinha PK. Orthodontists' assessment and management of patient compliance. Angle Orthod. 1998;68(2):115-122.

29. Southard KA, Tolley EA, Arheart KL, Hackett-Renner CA, Southard TE. Application of the Millon Adolescent Personality Inventory in evaluating orthodontic compliance. Am J Orthod Dentofacial Orthop. 1991;100(6):553-561.

30. Edgerton MT Jr, Knorr NJ. Motivational patterns of patients seeking cosmetic (esthetic) surgery. Plast Reconstr Surg. 1971;48(6):551-557.

31. Kiyak HA, West RA, Hohl T, McNeill RW. The psychological impact of orthognathic surgery: a 9-month follow-up. Am J Orthod. 1982;81(5):404-412.

32. Bagley J, Low K. Enhancing flossing compliance in college freshmen. Clin Prevent Dent. 1992(6);14:25-30.

33. Milgrom P, Vignehsa H, Weinstein P. Adolescent dental fear and control prevalence and theoretical implication. Behav Res Ther. 1992;30(4):367-373.

34. Portnoy S. Patient co-operation - how can it be improved? Br J Orthod. 1997;24(4):340-342.

\section{Publish your work in this journal}

Patient Preference and Adherence is an international, peer-reviewed, open access journal that focuses on the growing importance of patient preference and adherence throughout the therapeutic continuum. Patient satisfaction, acceptability, quality of life, compliance, persistence and their role in developing new therapeutic modalities and compounds to optimize clinical outcomes for existing disease states are major areas of interest for the journal. This journal has been accepted for indexing on PubMed Central. The manuscript management system is completely online and includes a very quick and fair peer-review system, which is all easy to use. Visit http://www dovepress.com/testimonials.php to read real quotes from published authors. 